\title{
O princípio constitucional da publicidade e o Processo Judicial Eletrônico (PJe): desafios para a garantia do direito fundamental de acesso à informação
}

The constitutional principle of advertising and the Eletronic Judicial Process (PJe): challenges for guaranteeing the fundamental right of access to information

El principio constitucional de la publicidad y el Proceso Judicial Electrónico (PJe): desafíos para garantizar el derecho fundamental de acceso a la información

\section{Resumo}

A implementação do Processo Judicial eletrônico (PJe), a partir da Resolução 185 do Conselho Nacional de Justiça (CNJ), trouxe uma série de mudanças relacionadas ao acesso às informações processuais, atingindo a todos, inclusive as partes. A Constituição da República de 1988 (CR/88) traz em seu texto o direito fundamental de acesso à justiça. Também prevê a publicidade dos atos da Administração Pública. Buscou-se problematizar o PJe frente aos mandamentos constitucionais, com o objetivo de contribuir para o debate doutrinário sobre o acesso à informação no âmbito do Poder Judiciário. Para tanto, foi utilizado o método jurídico-teórico e raciocínio dedutivo, com técnica de pesquisa bibliográfica. Verificou-se que a gestão do Poder Judiciário precisa pautar-se no desenvolvimento sustentável, a fim de que o acesso à justiça ocorra de forma plena.

Palavras-chave: Princípio da publicidade; Processo judicial eletrônico; Acesso à Informação; Acesso à justiça; Desenvolvimento sustentável.

\begin{abstract}
The implementation of the "PJe" from Resolution 185 of the National Council of Justice brought a series of changes related to access to procedural information, reaching everyone, including the parts. The Constitution of the Republic brings in its text the fundamental right of access to justice. It also foresees the Publicity of the acts of the Public Administration. We sought to problematize the "PJe" against the constitutional commandments, in order to contribute to the doctrinal debate on access to information within the Judiciary. For this, the legal-theoretical method and deductive reasoning were used, with bibliographic research technique. It was found that the administration of the Judiciary must be based on the principle of sustainable development in order for access to justice to occur fully.

Keywords: Publicity principle; Electronic judicial process; Access to information; Access to justice; Sustainable development.
\end{abstract}

\footnotetext{
Resumen

La implementación del Proceso Judicial electrónico (PJe), a partir de la Resolución 185 del Consejo Nacional de Justicia (CNJ), trajo una serie de cambios relacionados con el acceso a la información procesal, llegando a todos, incluidas las partes. La Constitución de la República de 1988 (CR / 88) incorpora en su texto el derecho fundamental de acceso a la justicia. También prevé la publicidad de los actos de la Administración Pública. Se buscó problematizar al PJe frente a los mandamientos constitucionales, con el objetivo de contribuir al debate doctrinal sobre el acceso a la información en el ámbito del Poder Judicial. Por lo tanto, se ha utilizado el método jurídico-teórico y el razonamiento deductivo con técnica de investigación bibliográfica. Se encontró que la gestión del Poder Judicial debe basarse en el desarrollo sostenible, para que el acceso a la justicia se produzca de manera integral.

Palabras clave: Principio publicitario; Proceso judicial electrónico; Acceso a la información; Acceso a la justicia; Desenvolvimiento sustentable.
} 


\section{Introdução}

O tema do presente trabalho é o estudo de uma das implicações da implementação do Processo Judicial eletrônico (PJe) na realidade social brasileira. Ao significar diversas mudanças para todos que participam dos processos judiciais, escolheu-se focar na questão do acesso das partes às informações processuais. Foi feito um recorte temático a fim de se analisar, com maior profundidade, o impacto do processo eletrônico na vida dos cidadãos que buscam a tutela jurisdicional.

Partindo do pressuposto que o acesso à justiça significa, necessariamente, a participação de todos os interessados, o acesso às informações processuais de forma satisfatória mostra-se fundamental. Contudo, o PJe demanda a quem queira acessá-lo diversos recursos tecnológicos, tanto de softwares quanto de hardwares. Nessa perspectiva, acaba excluindo as pessoas que não dominam e/ou não dispõem dos meios necessários. Dai advém o problema desse trabalho, qual seja, como garantir que as partes tenham acesso aos autos, tendo em vista os obstáculos que o próprio sistema oferece? Levando em consideração a sistemática do PJe surge o desafio de preservar a obtenção das informações processuais.

$\mathrm{O}$ interesse em estudar o tema surgiu da experiência de estágio do segundo autor numa secretaria de juízo do Tribunal de Justiça de Minas Gerais (TJMG). Ao discordar da seguinte orientação: "para a parte ter acesso aos autos eletrônicos deve procurar seu advogado", iniciou-se o interesse na pesquisa. Pretende-se contribuir com a discussão sobre o tema, apresentando novos argumentos. Justamente porque acredita-se que a Constituição da República de 1988 (CR/88) e Leis Federais garantem direitos que normas editadas por tribunais não podem desrespeitar. A atividade administrativa do Conselho Nacional de Justiça (CNJ) e dos órgãos jurisdicionais precisa pautar-se nas garantias constitucionais.

O objetivo do texto é problematizar o PJe sob o prisma do princípio constitucional do acesso à informação. Busca-se oferecer subsídios para o enfrentamento do problema apresentado.

No primeiro capítulo coteja-se os dispositivos constitucionais que tratam do acesso à tutela jurisdicional inscritos na $\mathrm{CR} / 88$, que garantem de forma expressa a publicidade dos atos praticados pelas instituições públicas, gerando deveres às últimas.

No segundo capítulo buscou-se compreender a implantação do PJe e as origens do movimento de informatização do Poder Judiciário. Nesse sentido, foram estudadas algumas normas federais que tratam do assunto, quais sejam, a Lei $\mathrm{n}^{\circ}$ 11.419/06, o Código de Processo Civil de 2015 (CPC/15), a Lei nº 12.527/11 e a Resolução nº 185 do CNJ.

No terceiro capítulo foi feita uma leitura da gestão do Poder Judiciário a partir do desenvolvimento sustentável. Buscou-se discorrer acerca dos valores que devem orientar o CNJ e os tribunais brasileiros para uma melhor satisfação do interesse público.

Por fim, propõe-se a instalação nas unidades do Poder Judiciário em todo o território nacional, de serviços de consulta aos processos eletrônicos, a fim de garantir aos cidadãos um pleno acesso à justiça.

\section{Metodologia}

Trata-se de uma pesquisa teórico-documental, com técnica dedutiva que buscou entender como as leis, normas infra legais e a doutrina abordam o tema do acesso às informações processuais. Como marco teórico, foram utilizadas as obras de Cármen Lúcia Antunes Rocha (1994) e Gomes e Estanislau (2019).

Assim, a pesquisa científica utilizou a doutrina e legislação. O raciocínio dedutivo emprega argumentos gerais para chegar às considerações finais. Essa técnica costuma ser utilizada por pesquisadores que empregam o raciocínio lógico, já que haverá uma relação lógica entre as premissas e as conclusões, segundo Mezzaroba e Monteiro (2009, p. 65). 


\section{Os Princípios Constitucionais}

$\mathrm{O}$ ordenamento jurídico brasileiro tem como pilar a $\mathrm{CR} / 88$, de modo que todas as normas jurídicas, atos da Administração Pública e as atividades dos Poderes Executivo, Legislativo e Judiciário devem seguir os mandamentos constitucionais.

A CR/88, por sua vez, traz em seu bojo princípios que foram insculpidos pelo legislador constituinte. Esses são valores que devem orientar os administradores públicos no exercício de suas funções, seja em qual dos poderes labutem. Na obra de Rocha tem-se uma importante colocação acerca dos princípios constitucionais:

Os princípios constitucionais, seu conteúdo, sua finalidade e, principalmente, sua normatividade jurídica e sua eficácia jurídica e social são, pois, os pontos fundamentais do modelo sistêmico constitucional, possibilitadores da adaptação do significado e continuidade da Constituição como instrumento necessário à experiência estatal e fundamental para a prevalência do Direito na relação politica entre as pessoas (Rocha, 1994, p. 17).

Percebe-se que os princípios constitucionais estão vinculados à efetividade dos comandos constitucionais e à materialização destes na realidade humana. O Estado, que busca cumprir as funções estabelecidas constitucionalmente, deve ter como norte os princípios constitucionais, sob pena de desvirtuamento da sua razão de existir e quebra da ordem estabelecida.

No presente trabalho defende-se que os princípios constitucionais da Administração Pública devem ser orientadores das atividades do Poder Judiciário. Tanto a prestação jurisdicional propriamente dita, quanto à atividade/função administrativa do Poder, devem se pautar pelos princípios da Moralidade, Eficiência, Legalidade, Impessoalidade e Publicidade. Cumpre ressaltar, que esse entendimento está calcado no conteúdo do art. 37, da CR/88. ${ }^{1}$ Entende-se ser fundamental frisar essa questão, pois lida-se, no Brasil, com uma cultura autoritária em relação aos tribunais e seus membros, o que gera uma dificuldade de enxergar os magistrados como servidores públicos investidos de jurisdição que devem devolver, em forma de tutela jurisdicional, o investimento que a população brasileira faz através do pagamento de tributos. Do mesmo modo, o corpo técnico que compõe a estrutura administrativa dos tribunais, é composto por servidores públicos, com direitos e deveres inerentes aos cargos, estabelecidos pela $\mathrm{CR} / 88$ e ratificados por leis e normas infra legais.

\subsection{O Poder Judiciário, a publicidade e o direito constitucional de acesso às informações processuais}

A CR/88 confere à Administração Pública um tratamento inovador em relação à Constituição anterior. Às instituições públicas se impõem, juridicamente, a construção e organização da prestação do serviço público de acordo com os princípios singulares elencados pela CR/88. Nesse sentido, conforme sustentado anteriormente, trabalha-se o Poder Judiciário como integrante da Administração Pública, sendo os órgãos jurisdicionais instituições que prestam serviço público aos cidadãos.

Como é sabido, o direito à informação nos órgãos públicos, o acesso à justiça, o direito à tutela jurisdicional e o dever do Estado em prestá-la estão previstos na CR/88. O art. 5º da CR/88 dispõe nos incisos XXXIII, XXXIV (alíneas a e b) e XXXV, acerca desses direitos fundamentais dos cidadãos e, ao mesmo tempo, deveres das instituições públicas ${ }^{2}$.

\footnotetext{
1 “Art. 37. A administração pública direta e indireta de qualquer dos Poderes da União, dos Estados, do Distrito Federal e dos Municípios obedecerá aos principios de legalidade, impessoalidade, moralidade, publicidade e eficiência [...]” (Brasil, 1988).

2 "Art. 5". Todos são iguais perante a lei, sem distinção de qualquer natureza, garantindo-se aos brasileiros e aos estrangeiros residentes no País a inviolabilidade do direito à vida, à liberdade, à igualdade, à segurança e à propriedade, nos termos seguintes: [...] XXXIII - todos têm direito a receber dos órgãos públicos informações de seu interesse particular, ou de interesse coletivo ou geral, que serão prestadas no prazo da lei, sob pena de responsabilidade, ressalvadas aquelas cujo sigilo seja imprescindivel à segurança da sociedade e do Estado; XXXIV - são a todos assegurados, independentemente do pagamento de taxas: a) o direito de petição aos Poderes Públicos em defesa de direitos ou contra ilegalidade ou abuso de poder; b) a obtenção de certidões em repartições públicas, para defesa de direitos e esclarecimento de situações de interesse pessoal; XXXV - a lei não excluirá da apreciação do Poder Judiciário lesão ou ameaça a direito [...]”' (Brasil, 1988).
} 
A doutrinadora Cármen Lúcia Antunes Rocha traz em sua obra considerações importantes acerca da publicidade e Administração Pública. Ao discorrer sobre o princípio supramencionado, sua relação com o Estado Moderno e a forma de governo como república, a professora assim escreve: “o Estado traz a publicidade da Administração na sua própria denominação. Pública diz-se ela. A publicidade é mais que um dos princípios constitucionais da Administração: é, assim, o seu próprio nome, a denotar-lhe a essência” (Rocha, 1994, p. 239).

Desse modo, compreende-se que os atos praticados dentro do corpo estatal precisam ser publicizados perante os cidadãos. A regra é a publicidade, o sigilo é a exceção. Historicamente, o Estado Brasileiro foi captado pelos interesses privados, gerando sequelas profundas nas instituições públicas e no modo como os entes privados e os indivíduos enxergam estas instituições e seus membros. Acerca deste fato histórico, destacando a inserção dos magistrados na sociedade colonial e, as relações sociais estabelecidas, escreveu o especialista Stuart. B. Schwartz:

A magistratura desempenhava um papel crucial na estrutura formal da organização. Apesar de ter parcialmente se
desenvolvido como classe social, a magistratura continuava a representar o governo real centralizado e tudo o que
havia de racional, profissional e categórico na burocracia. Se os desembargadores, que eram os mais altos e
supostamente os mais competentes magistrados profissionais, podiam ser subornados por laços de parentesco e
dinheiro, que esperança poderia haver para os magistrados menos importantes, para os governadores, coletores de
impostos e escrivães cujo conceito de cargo estava muito mais próximo de posse de uma propriedade rendosa? De
acordo com as normas burocráticas, os laços que prendiam um magistrado à sociedade violavam os padrões de
profissão, mas não era uma situação totalmente contrária ao funcionamento do governo. Talvez fosse o máximo que
se pudesse esperar de um regime autoritário no qual o aparato burocrático jamais suplantou a natureza fortemente
paternalística da sociedade ibérica. A situação persiste no Brasil de hoje onde o uso de pistolão está incorporado na
vida normal. As raízes disso, entretanto, estão lá longe, na herança colonial (Schwartz, 1979, 292-293).

Portanto é necessária a conscientização dos administradores públicos, vinculados a todos os poderes (legislativo, judiciário e executivo) de que o princípio constitucional da publicidade exige esforço para a construção de práticas e formas de trabalho que não violem a CR/88. Inclusive, quanto a implantação de recursos tecnológicos que visem tornar mais céleres e eficientes a prestação do serviço público, deve-se ter o cuidado de verificar se os cidadãos terão acesso a este serviço de forma não penosa, ou com grau mínimo de dificuldade, pois de que vale a eficiência, se o indivíduo interessado não consegue acessar o serviço? Ou ainda, há de se questionar se uma situação de dificuldade de acesso à informação comporta o conceito de eficiência.

Bobbio, em sua obra "A Era dos Direitos" efetiva profunda reflexão acerca dos direitos do homem. Fazendo uma análise do legado de Imannuel Kant, apresenta ao leitor apontamentos profundos, como por exemplo, "o aparecimento do direito que um povo tem de não ser impedido, por outras forças, de dar a si mesmo uma Constituição Civil que julga boa" (BOBBIO, 1992, p. 52). A concepção Kantiana da "Constituição boa” é aquela em que os que obedecem à lei devem também legislar, sendo este um direito natural do ser humano. A autonomia do ser humano nasce da obrigação de obedecer às leis que ele mesmo é legislador, de modo que a liberdade é enxergada por Kant como autonomia.

Bobbio defende no ensaio que dá nome à obra "A Era dos Direitos" que o debate importante no século XX acerca dos direitos do homem é: “[...] cada vez mais amplo, cada vez mais intenso, tão amplo que agora envolveu todos os povos da Terra, tão intenso que foi posto na ordem do dia pelas mais autorizadas assembleias internacionais - pode ser interpretado como um 'sinal premonitório' (signum prognosticum) do progresso moral da humanidade” (BOBBIO, 1992, p. 52).

O autor supramencionado afirma que não é um cego defensor do progresso, que a história humana é ambígua, que o conceito de moral é problemático e que a parte ruim da história da humanidade é maior que a parte boa. No entanto, afirma que a parte "clara" apareceu em alguns trechos da história e os esforços para a superação do mal advêm da consciência do estado precário em que o ser humano vive. Daí as diligências do homem para criar regras de conduta que tornem melhores as condições de vida. 
Por isso, as regras estabelecidas por uma sociedade e insculpidas na CR/88 devem ser interpretadas visando o bem comum. Não obstante toda a complexidade inerente ao Estado Democrático de Direito e à democracia representativa, os cidadãos são dirigidos pelas leis que produzem. Daí a importância do constante alinhamento aos direitos positivados na $\mathrm{CR} / 88 .^{3}$

\subsection{0 conteúdo do art. $5^{\circ}$ da Constituição da República de 1988 (incisos XXXIII, XXXIV e XXXV)}

$\mathrm{O}$ artigo $5^{\circ}$, da CR/88 dispõe em seus incisos acerca dos direitos e garantias fundamentais dos cidadãos. Trata-se de dispositivo constitucional extremamente importante e, por isso, conhecido pela sociedade brasileira em geral. Ressaltando que a CR/88 busca romper com um passado recente de graves lesões aos direitos e garantias fundamentais. Pois bem, o inciso XXXIII dispõe que: "Todos têm direito a receber dos órgãos públicos informações de seu interesse particular, ou de interesse coletivo ou geral, que serão prestadas no prazo da lei, sob pena de responsabilidade, ressalvadas aquelas cujo sigilo seja imprescindivel à segurança da sociedade e do Estado" (Brasil, 1988).

Por força disso, a CR/88 assegura a todos o direito de receber informações dos órgãos públicos. Desse modo, qualquer pessoa que procura o Poder Judiciário buscando informações sobre determinado processo deve ser devidamente atendida. Isso cresce de relevância quando o cidadão é parte no processo, pois tem interesse particular no andamento processual. Quando os autos são físicos e a parte vai até o balcão da secretaria, o servidor ou estagiário disponibiliza a vista dos autos no balcão. Caso o processo tramite em segredo de justiça, far-se-á a conferencia do documento de identificação para autorizar a vista dos autos. Assim é facultado à parte fazer anotações, tirar fotografias, ou mesmo solicitar à Ordem dos Advogados do Brasil (OAB) o serviço de fotocópias.

Ocorre que a implantação do PJe gerou modificações na forma de acesso às informações constantes nos autos. Como o processo é eletrônico, sendo necessário um certificado digital para acessá-lo em sua integralidade, surgem alguns problemas relacionados à informação. As partes não possuem essa ferramenta para acessar os autos. Desse modo, precisam solicitar ao atendente da secretaria ou então procurar seu advogado. Na primeira hipótese, se o funcionário não puder ou não quiser "mostrar" o processo para a parte, a ida ao fórum terá sido em vão. Por exemplo, saber o conteúdo e data do último despacho do magistrado. A segunda via, da busca pelo procurador, será tratada em tópico específico.

$\mathrm{O}$ inciso XXXIV do art. $5^{\circ}$ da CR/88 dispõe que: "São a todos assegurados, independentemente do pagamento de taxas: a) o direito de petição aos Poderes Públicos em defesa de direitos ou contra ilegalidade ou abuso de poder; $b$ ) a obtenção de certidões em repartições públicas, para defesa de direitos e esclarecimento de situações de interesse pessoal [...]" (Brasil, 1988).

Se a CR/88 assegura independentemente do pagamento de taxas o direito de petição aos Poderes Públicos, não é razoável pensar em dificultar ao cidadão o acompanhamento do processo seja em âmbito administrativo ou judicial. Isso caracteriza-se como flagrante violação à CR/88. As regras estabelecidas pelos Tribunais e pelo CNJ devem estar pautadas nos mandamentos constitucionais. A garantia constitucional prevista na alínea b do art. $5^{\circ}$, inciso XXXIV, da CR/88, de obtenção de esclarecimento de situações de interesse pessoal, não pode ser obstaculizada em razão de questões técnicas e/ou de organização do atendimento de serviço ao público pelos Tribunais, de modo que não há que se falar em acesso à justiça sem acesso à informação.

Por fim o inciso XXXV, também do art. $5^{\circ}$, da CR/88, determina que "a lei não excluirá da apreciação do Poder Judiciário lesão ou ameaça a direito" (Brasil, 1988). Corroborando o que foi dito anteriormente, é clara a percepção de que o 
legislador constitucional preocupou-se em garantir ao cidadão a proteção dos seus direitos em face de outros cidadãos e do Estado. O Poder Judiciário tem como premissa a inviolabilidade das garantias constitucionais.

\subsection{Acesso à Justiça e a relação cliente advogado}

A reflexão acerca do acesso à justiça e as mudanças causadas com a implantação do PJe têm sido objeto de preocupação dos juristas brasileiros. Gomes e Estanislau (2019, p. 2) estabeleceram discussões importantes sobre o problema. Eles relacionaram o PJe ao direito ao desenvolvimento sustentável, a boa governança e a sustentabilidade ${ }^{4}$. Ao realizar uma leitura crítica da situação atual, os autores afirmam que a informatização do processo leva à exclusão de todo cidadão que não foi alfabetizado, ou mesmo de todas as pessoas que não possuem computadores, acesso à internet e os demais recursos tecnológicos necessários à utilização do PJe.

Para Gomes e Estanislau: "como um retrocesso histórico o PJe corre o risco de excluir do acesso ao Poder Judiciário as pessoas menos favorecidas, limitando até mesmo seu acesso e utilização a elite possuidora de conhecimentos técnicos em informática e detentora de um privilégio econômico" (Gomes \& Estanislau, 2019, p. 3).

Desse modo, é preocupante se pensar em afastamento dos cidadãos da tutela jurisdicional. O acesso ao Poder Judiciário como garantia fundamental deve ser protegido por todas as pessoas. Quando há restrição ao direito de informação de qualquer parte acerca de um processo, ocorre o rompimento do estabelecido pela CR/88 em seu art. $5^{\circ}$, conforme já foi exposto. O presente trabalho defende que é direito do cidadão ter acesso ao processo em que é parte. O mínimo que o Estado precisa garantir é o direito à ampla defesa e ao contraditório para todos. Mas como falar nessas garantias se existe dificuldade no acesso às informações do processo? Gomes e Estanislau afirmam que "desta forma fica também restringido o poder de fiscalização dos cidadãos interessados, que não mais conseguem acompanhar as decisões judiciais, e as motivações existentes nas mesmas" (Gomes \& Estanislau, 2019, p. 4), de modo que há flagrante violação do princípio do acesso à justiça, inclusive do direito da sociedade acompanhar o trabalho dos magistrados.

Como trata-se do processo civil comum, em que o cidadão não goza de ius postulandi, necessita de estar assistido por advogado a fim de provocar a tutela jurisdicional. O Estatuto da OAB, Lei Federal $n^{\circ} 8.906 / 94^{5}$, disciplina a atividade profissional do advogado, suas garantias, direitos e deveres. Ocorre que o fato de uma pessoa contratar um advogado para assisti-la devidamente perante os órgãos jurisdicionais não exclui ou impede seu direito de acompanhar o andamento processual.

Quando a parte não consegue informações na secretaria do juízo fica automaticamente refém do advogado. Essa situação precária atenta contra a ordem constitucional e não é saudável nem para os cidadãos comuns nem para os advogados.

A fim de garantir plenamente o acesso ao Poder Judiciário é necessário que ao jurisdicionado seja resguardado a consulta às informações processuais. $\mathrm{O}$ acompanhamento dos atos processuais, dos documentos juntados aos autos e das manifestações, materializa a ampla defesa e o contraditório.

Por isso é preciso problematizar o PJe frente à manutenção dos direitos fundamentais inscritos na CR/88. Em um país com um abismo social como o Brasil, em que a desigualdade no acesso à tecnologia é uma realidade, urge construir caminhos para que o acesso à justiça não seja negado à sociedade.

\footnotetext{
${ }^{4}$ Para outros estudos sobre governança judicial, ver: Gomes \& Pereira, 2021, p. e379101119654.

5 “Art. 1'. São atividades privativas de advocacia: I - a postulação a órgão do Poder Judiciário e aos juizados especiais; II - as atividades de consultoria, assessoria e direção jurídicas. Art. $2^{\circ} \mathrm{O}$ advogado é indispensável à administração da justiça. $\$ 1^{\circ}$ No seu ministério privado, o advogado presta serviço público e exerce função social. $\S 2^{\circ}$ No processo judicial, o advogado contribui, na postulação de decisão favorável ao seu constituinte, ao convencimento do julgador, e seus atos constituem múnus público. $\S 3^{\circ}$ No exercício da profissão, o advogado é inviolável por seus atos e manifestações, nos limites desta lei" (Brasil, 1994).
} 


\section{A Implantação do Processo Judicial Eletrônico nos Órgãos do Poder Judiciário}

O presente trabalho busca fazer uma análise do PJe no Brasil, contrapondo-o ao princípio constitucional da publicidade. Isto é, uma leitura crítica do PJe a partir da CR/88, de modo que é importante entender como o Estado Brasileiro elaborou e buscou introduzir na realidade jurídica, o PJe. Percebe-se que a legislação federal e as resoluções do CNJ são as ferramentas utilizadas para a implantação e normatização do PJe.

O professor Almeida Filho, na obra intitulada "Processo Eletrônico e Teoria Geral do Processo Eletrônico: a informatização judicial no Brasil" faz um trabalho robusto de pesquisa acerca do Processo Eletrônico. Oportuniza ao leitor conhecer no âmbito jurídico e da tecnologia da informação como está ocorrendo a implantação dessa mudança em diferentes Estados Nacionais. Segundo Almeida Filho a informatização de atos processuais tem sua origem nos países de common law, notadamente os Estados Unidos da América (EUA), mas a experiência que tecnicamente mais se assemelha à brasileira é a italiana. Porém, no texto, há um apontamento acerca do modo de conduzir a implementação:

A inserção do Projeto Processo Civile Telematico e a apresentação das telas do programa que, repita-se, é gratuito e disponibilizado pelo Ministério da Justiça, têm por objetivo mostrar como a sistematização vem sendo realizada na Itália, ou seja, lenta e gradual. No Brasil, país de dimensão continental, pretendemos que o processo seja imediatamente inserido, muitas vezes de forma obrigatória e correndo o risco de ter um processo sobre outro processo (Almeida Filho, 2014, p. 112).

A crítica feita é pertinente levando-se em consideração a amplitude do território brasileiro, a quantidade de tribunais, as diversas realidades institucionais e a desigualdade socioeconômica vigente. Ainda:

Quando afirmamos ter um processo sobre outro processo estamos nos referindo à coexistência de dois modelos processuais: o dito convencional, ou físico, como alguns preferem e o eletrônico. Não atentamos para o alerta feito pelo Prof. Cândido Rangel Dinamarco e não nos preocupamos em analisar como se procede a questão da informatização judicial em outros países. O modelo português, por exemplo, tornou-se letra morta na lei, diante da burocracia informatizada criada pelo sistema. Resta-nos a questão: ou é procedimento e é especial, ou é processo! (Almeida Filho, 2014, p. 112).

Concorda-se com o professor, ressaltando que o processo eletrônico deve ser tratado como processo, não como outro tipo de procedimento, nem como plataforma de suporte para outro processo. Ou seja, toda construção doutrinária e jurisprudencial que sustenta a elaboração dos autos dos processos físicos deve também alicerçar os autos eletrônicos. Como forma de um processo existir no tempo e no espaço, sejam autos físicos ou eletrônicos, os direitos de petição, contraditório e ampla defesa, produção de provas e acompanhamento dos atos devem estar disponíveis ao jurisdicionado.

\subsection{A Lei no 11.419 de 2006 e a Lei no 12.527 de 2011 (Lei de Acesso à Informação)}

No dia 19 de dezembro de 2006 a Lei nº 11.419 (Lei do Processo Eletrônico) foi sancionada pelo Presidente da República, entrando em vigor no dia 19 de março de 2007. Na ementa, consta a informação de que a Lei dispõe sobre a informatização do processo judicial. Traz em seu conteúdo conceitos como meio eletrônico, diversas inovações acerca do funcionamento dos atos processuais, meios de divulgação dos mesmos, autenticidade das assinaturas e contagem de prazos. ${ }^{6}$

\footnotetext{
6 “Art. $1^{\circ} \mathrm{O}$ uso de meio eletrônico na tramitação de processos judiciais, comunicação de atos e transmissão de peças processuais será admitido nos termos desta Lei. $\S 1^{\circ}$ Aplica-se o disposto nesta Lei, indistintamente, aos processos civil, penal e trabalhista, bem como aos juizados especiais, em qualquer grau de jurisdição. $\S 2{ }^{\circ}$ Para o disposto nesta Lei, considera-se: I - meio eletrônico qualquer forma de armazenamento ou tráfego de documentos e arquivos digitais; II - transmissão eletrônica toda forma de comunicação a distância com a utilização de redes de comunicação, preferencialmente a rede mundial de computadores; III - assinatura eletrônica as seguintes formas de identificação inequívoca do signatário: a) assinatura digital baseada em certificado digital emitido por Autoridade Certificadora credenciada, na forma de lei específica; b) mediante cadastro de usuário no Poder Judiciário, conforme disciplinado pelos órgãos respectivos" (Brasil, 2006).
} 
Assim, essa Lei federal cria as balizas para que os tribunais desenvolvam as plataformas para o funcionamento do processo judicial de maneira informatizada.

Podem-se destacar alguns pontos importantes, como a verificação da autenticidade da assinatura de quem vier a praticar determinado ato processual, pois a validade do ato guarda relação com poderes para peticionar nos autos, por exemplo, bem como a questão da tempestividade de uma manifestação, questão esta sensível para o Processo Civil, pois pode ser declarada pelo juízo ou arguida pela parte contrária a preclusão ou intempestividade da petição.

Em 18 de novembro de 2011 foi sancionada pela Presidente da República a Lei n 12.527, cujo objetivo é materializar o acesso à informação previsto na CR/88. ${ }^{7}$ Percebe-se que o legislador busca garantir o cumprimento do direito fundamental de acesso à informação, obrigando que os servidores públicos trabalhem atendendo ao que está previsto na norma.

Os dispositivos legais trazem mandamentos importantes, como por exemplo, o que prevê o inciso I do art. $3^{\text {o: }}$ "a publicidade é preceito geral e o sigilo exceção" (Brasil, 2011). Partindo dessa premissa, o cidadão que busca determinada informação em qualquer instituição pública, tem o direito de recebê-la de forma satisfativa. Na hipótese de haver algum grau de sigilo, deve o servidor esclarecer o motivo de não poder fornecer tal acesso. Outros objetivos importantes previstos no art. $3^{\circ}$ da referida Lei guardam relação com o fomento da transparência da Administração Pública e a fiscalização da mesma pela sociedade. Tendo em vista a busca pela superação das desigualdades sociais que assolam o Brasil e os graves problemas vinculados à corrupção das instituições públicas é urgente a elaboração de medidas que garantam transparência dos atos realizados pelos agentes estatais.

\subsection{O Código de Processo Civil de 2015 e a Resolução no 185 do Conselho Nacional de Justiça}

O CPC/15 (Lei Federal n 13.105 de 2015) é a norma que rege o processo civil em todo o território nacional. Todos os sujeitos processuais, quais sejam, as partes, os magistrados, advogados, promotores e serventuários, devem agir de acordo com as regras dispostas no CPC/15. O primeiro artigo do diploma legal estabelece que o processo civil será disciplinado conforme a $\mathrm{CR} / 88$. Percebe-se que se trata de iniciativa garantidora da ordem constitucional e de sintonia do processo civil com os princípios constitucionais.

Na parte geral do CPC, Livro IV (Dos Atos Processuais), Capítulo I, Seção II, foram estabelecidas algumas regras para a prática eletrônica de atos processuais. O art. 194 dispõe que:

Os sistemas de automação processual respeitarão a publicidade dos atos, o acesso e a participação das partes e de seus procuradores, inclusive nas audiências e sessões de julgamento, observadas as garantias da disponibilidade, independência da plataforma computacional, acessibilidade e interoperabilidade dos sistemas, serviços, dados e informações que o Poder Judiciário administre no exercício de suas funções (Brasil, 2015).

Depreende-se da leitura que o CPC/15 ordena a publicidade dos atos e o acesso das partes. O mandamento está de acordo com o previsto na Lei de Acesso à informação (Lei no 12.527/11), ou seja, é premissa lógica que as partes tenham acesso de forma fácil aos atos processuais. Os regimentos internos dos tribunais e outras normas expedidas pelos mesmos não podem contrariar o disposto no $\mathrm{CPC} / 15$.

\footnotetext{
7 “Art. $1^{\circ}$ Esta Lei dispõe sobre os procedimentos a serem observados pela União, Estados, Distrito Federal e Municipios, com o fim de garantir o acesso a informações previsto no Art. $1^{\circ}$ Esta Lei dispõe sobre os procedimentos a serem observados pela União, Estados, Distrito Federal e Municipios, com o fim de garantir o acesso a informações previsto no inciso XXXIII do art. $5^{\circ}$, no inciso II do $\S 3^{\circ}$ do art. 37 e no $\S 2^{\circ}$ do art. 216 da Constituição Federal. Parágrafo único. Subordinam-se ao regime desta Lei: I - os órgãos públicos integrantes da administração direta dos Poderes Executivo, legislativo, incluindo as Cortes de Contas, e Judiciário e do Ministério Público; II - as autarquias, as fundações públicas, as empresas públicas, as sociedades de economia mista e demais entidades controladas direta ou indiretamente pela União, Estados, Distrito Federal e Municípios. Art. $3^{\circ}$ Os procedimentos previstos nesta Lei destinam-se a assegurar o direito fundamental de acesso à informação e devem ser executados em conformidade com os princípios básicos da administração pública e com as seguintes diretrizes: [...]” (Brasil, 2011).
} 
Os art. 198 disciplina obrigação dos órgãos do Poder Judiciário em relação à prestação de serviço aos cidadãos interessados. Considera-se válido citá-lo literalmente, em razão do conteúdo.

Art. 198. As unidades do Poder Judiciário deverão manter gratuitamente, à disposição dos interessados, equipamentos necessários à prática de atos processuais e à consulta e ao acesso ao sistema e aos documentos dele constantes. Parágrafo único. Será admitida a prática de atos por meio não eletrônico no local onde não estiverem disponibilizados os equipamentos previstos no caput (Brasil, 2015).

Resta claro que o CPC/15 impõe ao Poder Judiciário o fornecimento de meios para a consulta aos sistemas que comportam os autos eletrônicos, de modo que, como afirmado anteriormente, os tribunais não podem editar normas que contrariem Lei Federal. Não é justo prejudicar o acesso à informação processual alegando-se falta de estrutura para disponibilizá-la.

Através da Resolução no 185 do CNJ foi instituído o PJe. Nessa norma foram estabelecidas várias regras acerca de seu funcionamento e definidos conceitos vinculados à utilização do mesmo. Na exposição dos motivos da Resolução, verifica-se a referência a requisitos como: "[...] celeridade e qualidade da prestação jurisdicional e necessidade de racionalização da utilização de recursos orçamentários pelos órgãos do Poder Judiciário" (CNJ, 2013). Verifica-se que tais situações são relevantes para o contexto de administração da justiça e gestão do Poder Judiciário. O princípio da razoável duração do processo inscrito na $\mathrm{CR} / 88$ necessita realmente ser objeto de preocupação do $\mathrm{CNJ}$, bem como a melhor eficiência na gestão dos recursos públicos.

Acontece que alguns pontos da norma merecem também destaque, em razão da problemática abordada nesse trabalho. $\mathrm{O}$ art. $6^{\circ}$ dispõe que "para acesso ao PJe é obrigatória a utilização de assinatura digital a que se refere o art. $4^{\circ}, \S^{\circ}$ desta Resolução, com exceção das situações previstas no $\S 4^{o}$ deste artigo" (CNJ, 2013). Ora, tal norma denota constante contradição quando defrontada com a Lei de Acesso à Informação, pois o acesso ao sistema não pode ser limitado àqueles que possuam assinatura digital.

\section{O Desenvolvimento Sustentável como Direito}

A partir da Segunda Guerra Mundial a humanidade envidou esforços para a construção de caminhos de crescimento econômico e de respeito aos direitos humanos diferentes dos já conhecidos. Segundo Marco e Mezzaroba a criação da Organização das Nações Unidas (ONU) está relacionada à garantia da paz mundial, em sintonia com os direitos humanos. Porém, na década de 1970 é que houve um marco da busca pelo desenvolvimento sustentável:

[...] em 1972 foi realizado em Estocolmo, na Suécia, o evento mais emblemático em busca de uma visão ecológica do desenvolvimento com sustentabilidade, ou seja, uma visão holística que insere o humano numa relação de pertencimento e interdependência do ambiente natural. Foi a Primeira Conferência Mundial sobre o Homem e o Meio Ambiente (Marco \& Mezzaroba, 2017, p. 327).

Segundo os autores, o desenvolvimento sustentável guarda compromissos com a "justiça social, econômica e ambiental do presente e do futuro" (Marco \& Mezzaroba, 2017, p. 329), em contraposição ao paradigma do desenvolvimento puramente econômico. A humanidade como integrante do planeta Terra, deve inserir-se de forma harmônica no todo. Gomes e Ferreira prelecionam que "a sustentabilidade denota uma preocupação internacional em promover o pleno desenvolvimento sustentável dos povos e das comunidades de modo a preservar o meio ambiente equilibrado para as presentes e futuras gerações" (Gomes \& Ferreira, 2017, p. 94). Desse modo, apreende-se que as iniciativas estatais, as políticas públicas e as ações privadas, devem pautar-se pelo princípio norteador do desenvolvimento sustentável. 
Ao mesmo tempo em que se mostra como princípio norteador para a humanidade, o desenvolvimento sustentável é um direito fundamental positivado na $\mathrm{CR} / 88$, no art. $225 .{ }^{8}$ Ainda que não esteja escrito de forma expressa no conteúdo do dispositivo, fica claro que os objetivos do desenvolvimento sustentável estão concretizados no referido artigo. Percebe-se que o texto é semelhante ao editado em 1988 pela Comissão Mundial Sobre Meio Ambiente e Desenvolvimento. O desafio é garantir de forma satisfatória a qualidade de vida da atual geração sem comprometer as gerações vindouras. Em razão do texto constitucional trazer como direito fundamental o desenvolvimento sustentável, cria-se para o Estado Brasileiro a obrigação de se amoldar isso e contribuir para que a sociedade e as instituições privadas caminhem dessa forma.

\subsection{A dimensão jurídico-política}

Segundo a doutrina especializada, o desenvolvimento sustentável abarca diversas dimensões, quais sejam: a dimensão social, a dimensão econômica, a dimensão ambiental, a dimensão ética e a dimensão jurídico-política. A partir da obra de Gomes e Ferreira, busca-se explicitar essa quinta dimensão, em razão da sua importância para o presente trabalho. De acordo com os autores, a dimensão jurídico-política advém da junção das quatro primeiras dimensões. É uma "[...] determinação principiológica vinculante que visa ao aperfeiçoamento da tutela efetiva dos direitos fundamentais para que possam se materializar em bem-estar para as presentes e futuras gerações, num prisma de proteção da vida em suas diferentes formas" (Gomes \& Ferreira, 2017, p. 96).

Para que os direitos fundamentais se concretizem é preciso que seja franqueada a participação de um maior número de pessoas nas decisões e que as instituições públicas vinculadas aos Poderes Legislativo, Executivo e Judiciário estejam abertas à atividade democrática.

A dimensão jurídico-política busca resguardar o conjunto de direitos sociais e políticos previstos na CR/88, justamente por se tratarem de garantias de uma vida digna, convivência social saudável, relação de trabalho decente, enfim, condições para que os indivíduos cresçam intelectualmente e contribuam para que as gerações futuras também gozem desses direitos.

Nesse sentido, como tem sido defendido ao longo deste trabalho, o acesso pleno à justiça mostra-se elemento crucial para o desenvolvimento sustentável. Garantir que os cidadãos busquem o Poder Judiciário e obtenham uma prestação de serviço público de qualidade constitui-se tarefa elementar. Desse modo, é salutar que a política de gestão dos órgãos jurisdicionais, por impactarem diretamente a população brasileira, seja fundamentada na garantia dos direitos fundamentais.

\subsection{Gestão do Poder Judiciário}

O Direito Administrativo preocupou-se em organizar o papel constitucional da Administração Pública. Na doutrina administrativista encontra-se a classificação em funções típicas e atípicas dos Poderes da República. Oliveira esclarece que:

O poder normativo ou regulamentar é a prerrogativa reconhecida à Administração Pública para editar atos administrativos gerais para fiel execução das leis. Tradicionalmente, é reconhecida a possibilidade de órgãos e entidades localizadas institucionalmente fora do âmbito do Poder Legislativo exercerem, também, poder normativo. Trata-se, em verdade, de uma consequência do caráter relativo do princípio da separação de poderes que, segundo a doutrina do checks and balances, permite a cada um dos 'Poderes' o exercício de funções atípicas de forma a

\footnotetext{
8 “Art. 225. Todos têm direito ao meio ambiente ecologicamente equilibrado, bem de uso comum do povo e essencial à sadia qualidade de vida, impondo-se ao Poder Público e à coletividade o dever de defendê-lo e preservá-lo para as presentes e futuras gerações. $\S 1^{\circ}$ Para assegurar a efetividade desse direito, incumbe ao Poder Público: I - preservar e restaurar os processos ecológicos essenciais e prover o manejo ecológico das espécies e ecossistemas; II preservar a diversidade e a integridade do patrimônio genético do País e fiscalizar as entidades dedicadas à pesquisa e manipulação de material genético; III - definir, em todas as unidades da Federação, espaços territoriais e seus componentes a serem especialmente protegidos, sendo a alteração e a supressão permitidas somente através de lei, vedada qualquer utilização que comprometa a integridade dos atributos que justifiquem sua proteção; IV - exigir, na forma da lei, para instalação de obra ou atividade potencialmente causadora de significativa degradação do meio ambiente, estudo prévio de impacto ambiental, a que se dará publicidade; [...]”' (Brasil, 1988).
} 
controlar o outro 'Poder'. Ou seja, cada 'Poder' exerce funções típicas, correspondentes ao seu nome (Poder Executivo executa a lei; o Legislativo cria as leis, inovando na ordem jurídica; e o Judiciário resolve, com definitividade, as lides, além de controlar a constitucionalidade de leis e atos normativos), bem como funções atípicas que seriam, em princípio, inerentes aos outros Poderes (Oliveira, 2018, p. 312).

Claramente a função precípua do Poder Judiciário é a função judiciária (proferir decisões judiciais). Ocorre que o Poder Judiciário exerce também a função normativa, de autogoverno, controle interno da sua atividade e dos seus membros.

Os Tribunais de todo o país, regulam, através dos seus regimentos internos, portarias, resoluções, provimentos, e outras normas, o funcionamento dos mesmos. Desse modo, a função normativa mostra-se importante porque vincula os magistrados e servidores das unidades judiciárias, bem como impactam toda a sociedade, na medida em que definem as regras da prestação de um serviço público.

O CNJ, criado a partir da Emenda Constitucional (EC) no 45 de 2004, disposto no art. 103-B, da CR/88, tem como missão "o controle da atuação administrativa e financeira do Poder Judiciário e do cumprimento dos deveres funcionais dos juízes” (Brasil, 1988). Percebe-se que a partir da sua criação, parte do poder normativo dos tribunais foi transferido a este órgão. Conforme extrai-se do sítio oficial do Conselho, este busca aperfeiçoar o trabalho do Poder Judiciário brasileiro, conferindo-lhe maior grau de transparência e efetividade. Percebe-se que a gestão da Justiça tem sido objeto de preocupação da sociedade e que as normas que regulamentam o Poder impactam necessariamente a todos que buscam tutela jurisdicional. Neste sentido, faz-se necessário destacar alguns pontos acerca da regulamentação do Poder Judiciário, a fim de aprofundar melhor no tema.

Pereira (2016) em trabalho intitulado “Autogoverno, Regulação, Função Normativa e Independência Interna no Judiciário" analisou os conceitos inscritos no título. Apresenta ao leitor a estruturação do Poder ao longo da história brasileira. A gestão do Poder Judiciário, as tensões com o Poder Executivo, a hierarquização da administração da Justiça Pátria e o afastamento dos magistrados de $1^{\circ}$ grau da escolha dos representantes diretivos.

Ao fazer um panorama a partir da criação do CNJ o autor identifica que

No sistema judiciário brasileiro, ao lado das cúpulas dos tribunais, o Conselho Nacional de Justiça, o Conselho da Justiça Federal e o Conselho da Justiça do Trabalho exercem parcela do autogoverno, destacando-se que os conselhos integram o Judiciário como órgãos de administração e não de decisão jurisdicional. Todavia, não são controle externo e, portanto, a sua atuação não viola o princípio da separação de poderes, seja qual for a leitura que se queira emprestar a ele na atualidade (Pereira, 2016, p. 31).

Trata-se de competência insculpida na CR/88 e dissecada pelos administrativistas o controle interno de um Poder sobre si mesmo. Não deixa de ser aferição de legalidade das atividades exercidas pelos órgãos componentes de determinado poder.

Compreende-se que essa atividade de gestão e controle do Poder Judiciário deve calcar-se nos princípios constitucionais, especialmente no desenvolvimento sustentável. As Resoluções do CNJ e os demais atos normativos editados pelos tribunais brasileiros precisam estar em sintonia com a construção de uma sociedade justa e democrática. Todas as normas criadas com o fito de promover o autogoverno do Poder demandam uma valoração e reformulação a fim de se tornarem compatíveis com os mandamentos constitucionais de acesso a justiça e acesso à informação.

Neste âmbito de discussão é importante trazer ao debate reflexões acerca dos servidores públicos que integram o Poder Judiciário, bem como implicações de deveres inscritos no CPC/15.

Conforme preleciona o caput do art. 37, da CR/88, a Administração Pública é formada por todos os órgãos vinculados aos Poderes Legislativo, Executivo e Judiciário, de modo que os servidores que compõem os quadros das instituições públicas são agentes que prestam serviço público. 
Nesse sentido, é necessário destacar que tanto magistrados como aqueles que fazem parte do corpo técnico dos tribunais brasileiros são agentes públicos. Aos primeiros é conferido pela CR/88 o exercício da jurisdição, com todas as prerrogativas previstas do art. 93, da CR/88. Já os segundos exercem as funções fundamentais de retaguarda à administração da justiça, quais sejam, o cumprimento de mandados judicias, de decisões, atendimento ao público e assessoramento.

Importante destacar a tarefa de atendimento às pessoas que procuram os fóruns e demais unidades do Poder Judiciário. A fim de materializar o que está previsto na Lei de Acesso à Informação e no CPC/15, conforme antes destacado, é premente que as disposições presentes em tais normas sejam obedecidas pelos órgãos do Poder Judiciário.

Em razão do que se afirma neste tópico, entende-se que é necessária a estruturação de um serviço de consulta processual nos fóruns brasileiros. Percebe-se que é transparente o conteúdo do art. 198, do CPC/15, qual seja: "as unidades do Poder Judiciário deverão manter gratuitamente, à disposição dos interessados, equipamentos necessários à prática de atos processuais e à consulta e ao acesso ao sistema e aos documentos dele constantes" (Brasil, 2015). Dessa forma, o Poder Judiciário é obrigado pela principal Lei federal que disciplina o processo civil pátrio, a ofertar aos cidadãos os instrumentos necessários à consulta dos autos que lhes interessem, isso como política pública sustentável ${ }^{9}$. Respeitando-se logicamente os feitos classificados com grau de sigilo, que deverão ser disponibilizados somente às partes devidamente qualificadas.

\section{Considerações Finais}

Em razão do princípio da publicidade e dos direitos fundamentais previstos na $\mathrm{CR} / 88$, as transformações e melhoramentos efetivados pelos órgãos da Administração Pública devem ser precedidos de cuidados. Verificou-se que a implantação do Pje objetivou melhorar a eficiência do Poder Judiciário, porém o texto constitucional prevê que a todos sejam asseguradas informações nos órgãos estatais de modo que a Justiça não pode furtar-se ao dever inscrito na CR/88.

Desse modo, buscou-se fazer uma discussão conceitual acerca das normas que regulamentam o PJe frente a CR/88, tendo como parâmetro intelectual a busca pelo desenvolvimento sustentável. Assim, verificou-se que algumas normas jurídicas trazem mandamentos importantes para a efetivação de um processo judicial sustentável.

Afirma-se que Lei $\mathrm{n}^{\mathrm{o}} 12.527 / 11$ e o CPC/15 estão alinhados aos princípios da CR/88. Isso porque estabelecem obrigações para os entes públicos de franquear o acesso à informação de forma satisfatória. Defende-se que as regulamentações expedidas pelo $\mathrm{CNJ}$ e pelos tribunais pátrios precisam alinhar-se às leis federais citadas.

Desse modo, as obrigações inscritas na Lei de Acesso à Informação e no CPC/15 devem ser efetivadas pelo sistema de justiça brasileiro. Cabe ao $\mathrm{CNJ}$ e aos tribunais garantir que as partes tenham acesso às informações processuais. $\mathrm{O}$ que se defende no presente trabalho é que o acesso à informação como pressuposto do acesso à justiça, direito fundamental insculpido na CR/88, deve ser cuidadosamente tratado pelo legislador stricto sensu, bem como pelos gestores do CNJ e dos tribunais brasileiros. Trata-se de desafio posto aos que labutam na administração da justiça, garantir que a modernização não viole a $\mathrm{CR} / 88$.

Para que se construa uma democracia cada vez mais sólida é necessária a participação de todos. A tutela jurisdicional eficaz é um dos pilares do desenvolvimento sustentável de uma sociedade. E faz parte do exercício da cidadania a fiscalização dos magistrados pelos cidadãos. Por isso o devido acesso à justiça tem uma série de implicações para o desenvolvimento de uma sociedade.

Por fim, propõe-se que sejam instalados nas unidades do Poder Judiciário em todo o território nacional serviços de consulta aos processos eletrônicos, com equipamentos adequados e pessoal treinado, a fim de que seja um recurso efetivo a

${ }^{9}$ Para estudar o conceito de políticas públicas sustentáveis, ver: Gomes \& Ferreira, 2018, p. 155-178 
disposição dos cidadãos brasileiros. E que tal serviço seja visto pelos jurisdicionados como um direito e pelo Poder Judiciário como um dever.

\section{Agradecimentos}

Trabalho financiado pelo Edital $n^{\circ}$ 03/2020 de Incentivo à Pesquisa da Escola Superior Dom Helder Câmara, resultante dos Grupos de Pesquisas (CNPQ): Responsabilidade Civil e Processo Ambiental (RECIPRO), NEGESP, Metamorfose Jurídica e CEDIS (FCT-PT).

\section{Referências}

Almeida Filho, J. C. de A. (2014) Processo eletrônico e teoria geral do processo eletrônico: a informatização judicial no Brasil. Forense.

Bobbio, N. (1992) A Era dos Direitos. Tradução de Carlos Nelson Coutinho. Campus.

Brasil. Constituição (1988). Constituição da República Federativa do Brasil. Diário Oficial, Brasília.

Brasil. (1994). Lei no 8.906, de 4 de julho de 1994. Dispõe sobre o Estatuto da Advocacia e a Ordem dos Advogados do Brasil (OAB). Diário Oficial, Brasília. http://www.planalto.gov.br/ccivil_03/Leis/L8906.htm.

Brasil. (2006). Lei ${ }^{\circ} 11.419$, de 19 de dezembro de 2006. Dispõe sobre a informatização do processo judicial; altera a Lei ${ }^{\circ} 5.869$, de 11 de janeiro de 1973 Código de Processo Civil; e dá outras providências. Diário Oficial da União, Brasília. http://www.planalto.gov.br/ccivil_03/_ato20042006/2006/lei/111419.htm.

Brasil. (2011). Lei $\mathrm{n}^{\circ} 12.527$, de 18 de novembro de 2011. Regula o acesso a informações previsto no inciso XXXIII do art. $5^{\circ}$, no inciso II do $§ 3^{\circ}$ do art. 37 e no $§ 2^{\circ}$ do art. 216 da Constituição Federal; altera a Lei $n^{\circ} 8.112$, de 11 de dezembro de 1990; revoga a Lei ${ }^{\circ} 11.111$, de 5 de maio de 2005 , e dispositivos da Lei no 8.159, de 8 de janeiro de 1991; e dá outras providências. Diário Oficial da União, Brasília. http://www.planalto.gov.br/ccivil_03/_ato20112014/2011/lei/112527.htm.

Brasil. (2015). Lei no 13.105 de 16 de março de 2015. Código de Processo Civil. Diário Oficial da União. http://www.planalto.gov.br/ccivil_03/_ato20152018/2015/lei/l13105.htm.

Comissão Mundial sobre Meio Ambiente e Desenvolvimento (CMMAD). (1991). Nosso futuro comum. Editora da Fundação Getúlio Vargas. (2a ed.)

Conselho Nacional de Justiça (CNJ). (2013). Resolução $n^{o}$ 185, de 18 de dezembro de 2013. Institui o Sistema Processo Judicial Eletrônico - PJe como sistema de processamento de informações e prática de atos processuais e estabelece os parâmetros para sua implementação e funcionamento. Brasília: Conselho Nacional de Justiça. https://atos.cnj.jus.br/atos/detalhar/atos-normativos?documento=1933.

Gava. B. S. (2019). Supremo Tribunal Federal e Conselho Constitucional: A publicidade e o segredo no controle de constitucionalidade. Universidade Federal do Rio Grande do Sul. http://hdl.handle.net/10183/200001

Gomes, M. F \& Estanislau, F. N. (2019). O processo judicial eletrônico, o direito ao desenvolvimento e a boa governança: o caminho para a Sustentabilidade. Revista da Faculdade de Direito da Universidade Federal de Goiás, Goiânia, 43, 1-16. https://www.revistas.ufg.br/revfd/article/view/44591.

Gomes, M. F \& Ferreira, L. J. (2017). A dimensão jurídico-política da sustentabilidade e o direito fundamental à razoável duração do procedimento. Revista do Direito, Santa Cruz do Sul, 2(52), 93-111. http://dx.doi.org/10.17058/rdunisc.v2i52.8864.

Gomes, M. F \& Ferreira, L. J. (2018). Políticas públicas e os objetivos do desenvolvimento sustentável. Revista Direito e Desenvolvimento, 9(2), 155-178. https://doi.org/10.25246/direitoedesenvolvimento.v9i2.667.

Gomes, M. F. \& Pereira, I. L. de C. (2021). Governança judicial como solução efetiva à oralidade no processo civil brasileiro: jurisdição sustentável. Research, Society and Development, 10(11), e379101119654. https://doi.org/10.33448/rsd-v10i11.19654

Marco, C. M. \& Mezzaroba, O. (2017). O Direito Humano ao Desenvolvimento Sustentável: Contornos Históricos e Conceituais. Veredas do Direito, Belo Horizonte, 14(29), 232-349. http://www.domhelder.edu.br/revista/index.php/ veredas/article/view/1066.

Mezzaroba, O. \& Monteiro, C. S. (2009). Manual de metodologia da pesquisa no direito. Saraiva. (5a ed.)

Oliveira, R. C. R. (2018). Curso de direito administrativo. Forense. (2a ed.).

Pereira, A. M. G. (2016). Autogoverno, Regulação, Função Normativa e Independência Interna no Judiciário. Revista de Direito Setorial e Regulatório, Brasília. 2(2), 1-46. http://periodicos.unb.br/index.php/rdsr/article/download/19223/17726.

Rocha, C. L. A. (1994) Princípios constitucionais da administração pública. Del Rey.

Schwartz, S. B. (1979) Burocracia e sociedade no Brasil Colonial: a Suprema Corte da Bahia e seus Juízes: 1609-1751. Perspectiva. 